\title{
The Life of Professor C. Miller Fisher: A Giant of Stroke Medicine
}

\author{
Dong-Eog Kim
}

Department of Neurology, Dongguk University Ilsan Hospital, Goyang, Korea

I am a long-time admirer of Dr. Caplan, one of the greatest teachers in vascular neurology. When asked to review his book "C. Miller Fisher: Stroke in the 20th Century" (Figure 1), I was eager to read this book and learn about the life of the very teacher of Dr. Caplan and many other eminent neurologists. As the author describes in the Introduction, this book is Dr. Fisher's story, including his life, his method of study and research, and his contributions, and a biography of stroke as it evolved during the 20th century.

Dr. Fisher was born in Ontario, Canada, in 1913. He went to the University of Toronto College and Medicine when there was therapeutic nihilism in stroke. When he did his internship at the

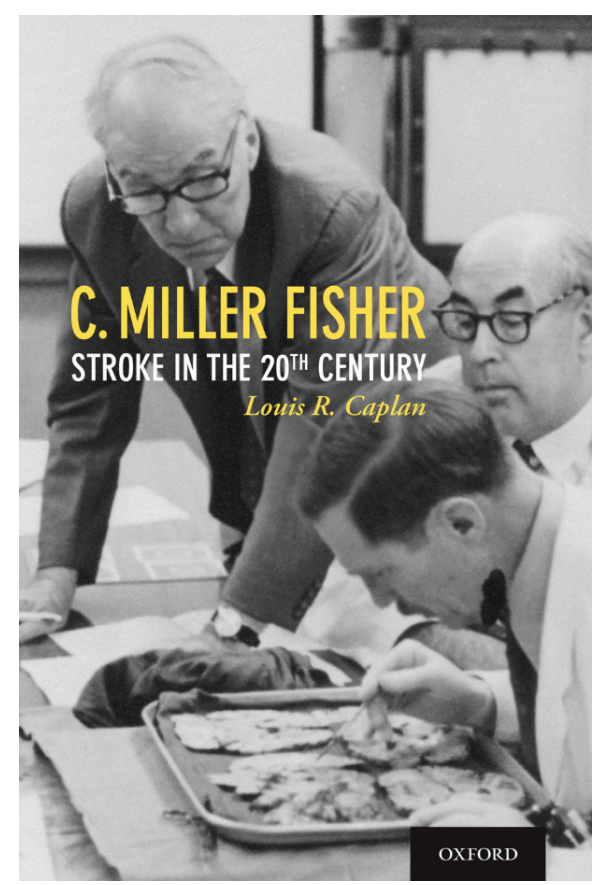

Figure 1. The book cover: looking at a brain after sectioning. Raymond Adams is standing. E. P. Richardson is seated and viewing the brain slices. Fisher is peering over Richardson's head.
Henry Ford Hospital, Detroit, MI, USA, in the late 1930s, there were no antibiotics except for sulfonamides, no antihypertensives, antidepressants, anticoagulants, or anticonvulsants. The book helps readers appreciate how hard it must have been for young Dr. Fisher to start his medical career from scratch. During World War II, Dr. Fisher served as an army doctor in the Royal Canadian Navy and then spent 3.5 years in a prisonerof-war camp in Germany. When he was liberated, he was determined to be productive and not waste further time by focusing on medicine.

The book vividly shows how he made each day meaningful for several years in Canada (at the Montreal Neurological Institute and the Montreal General Hospital) and for more than a half century in the USA (mostly at the Massachusetts General Hospital). Dr. Fisher considered neurology and stroke his main work in those days. He regarded his clinical and laboratory works as a full-time job, starting early in the morning and lasting until late at night for at least 6 days a week and often on all 7 days. In line with his strong work ethics, this book also shows how he liked people, including trainees, colleagues, and patients.

In 1998, Dr. Fisher prepared "101 separate contributions," a list of his own contributions for a Canadian Medical Hall of Fame biographer. As the author summarized, Dr. Fisher made sentinel observations on the carotid artery disease, transient visual symptoms, the distribution of atherosclerotic plaques and narrowings in the neck and head, and cerebral embolism. In addition, he developed the fundamental knowledge of the pathophysiology of lacunar infarction by reviewing a huge amount of continuous, uninterrupted serial sections of large blocks of brain tissue. In addition to developing the aforementioned core concepts of modern stroke medicine, the book mentions other key neurological knowledge that Dr. Fisher first described or substantially reinforced: Miller Fisher syndrome, wrong-way eyes, normal pressure 
hydrocephalus, the string sign, the cord sign, the one-and-a-half syndrome, cervical and cranial arterial dissections, gait abnormalities, and neurological examination of the stuporous patient.

I thoroughly enjoyed reading the book, which shows how Dr. Fisher, a legendary teacher for all neurologists, founded modern stroke medicine. It was also interesting to learn how the great teacher lived his life as a lifelong student, as he mentioned: "Hardly a day passed without some, new for me, observation. Each day I became a more knowledgeable clinician, a better neurologist." I strongly recommend this book to not only neurologists and neurosurgeons but also every doctor and every student who wants to be a doctor.

Correspondence: Dong-Eog Kim

Department of Neurology, Dongguk University Ilsan Hospital, 27 Dongguk-ro, Ilsandong-gu, Goyang 10326, Korea

Tel: +82-31-961-7207

Fax: +82-31-961-7212

E-mail: kdongeog@duih.org

http://orcid.org/0000-0002-9339-6539

The author has no financial conflicts of interest. 